\title{
Something New to Offer: Renal Denervation
}

\author{
Norman K. Hollenberg
}

Published online: 20 July 2011

(C) Springer Science+Business Media, LLC 2011

Symplicity HTN-1 Investigators: Catheter-based renal sympathetic denervation for resistant hypertension: durability of blood pressure reduction out to $\mathbf{2 4}$ months. Hypertension 2011, 57:911-917.

Keywords: Hypertension; Renal sympathetic denervation; Blood pressure; Durability; Follow-up; Complications; Cohort study; Treatment

\begin{abstract}
Renal sympathetic hyperactivity is seminal in the maintenance and progression of hypertension. Catheter-based renal sympathetic denervation has been shown to significantly reduce blood pressure (BP) in patients with hypertension. Durability of effect beyond 1 year using this novel technique has never been reported. A cohort of 45 patients with resistant hypertension (systolic $\mathrm{BP} \geq 160 \mathrm{~mm} \mathrm{Hg}$ on $\geq 3$ antihypertension drugs, including a diuretic) has been originally published. Herein, we report longer-term follow-up data on these and a larger group of similar patients subsequently treated with catheter-based renal denervation in a nonrandomized manner. We treated 153 patients with catheter-based renal sympathetic denervation at 19 centers in Australia, Europe, and the United States. Mean age was $57 \pm 11$ years, $39 \%$ were women, $31 \%$ were diabetic, and $22 \%$ had coronary artery disease. Baseline values included mean office BP of 176/98 $\pm 17 / 15 \mathrm{~mm} \mathrm{Hg}$, mean of 5 antihypertension medications, and an estimated glomerular filtration rate of $83 \pm 20 \mathrm{~mL} / \mathrm{min}$ per $1.73 \mathrm{~m}^{2}$. The median
\end{abstract}

\footnotetext{
N. K. Hollenberg $(\bowtie)$

Departments of Medicine and Radiology,

Harvard Medical School, Brigham and Women's Hospital,

Mailstop PBB1-Rad Building, 15 Francis Street,

Boston, MA 02115, USA

e-mail: djpagecapo@rics.bwh.harvard.edu
}

time from first to last radiofrequency energy ablation was 38 minutes. The procedure was without complication in $97 \%$ of patients (149 of 153). The 4 acute procedural complications included 3 groin pseudoaneurysms and 1 renal artery dissection, all managed without further sequelae. Postprocedure office BPs were reduced by 20/10, 24/11, 25/11, 23/11, 26/14, and 32/14 $\mathrm{mm} \mathrm{Hg}$ at 1, 3, 6, 12, 18, and 24 months, respectively. In conclusion, in patients with resistant hypertension, catheter-based renal sympathetic denervation results in a substantial reduction in BP sustained out to $\geq 2$ years of follow-up, without significant adverse events.

\section{Editor's Comment:}

What an extraordinary experience writing this note has been. The results of this study were extraordinarily good. The positive response occurred in over $90 \%$ of patients, and there was essentially no pathology. Although there are as yet no controlled clinical trials, it is difficult to believe that these observations are the product of a placebo response. The results are too good.

If there is a concern about this report, it stems from the same source: the results are too good. Only time and an appropriate study will answer that question.

Some additional questions require discussion. Do the individual elements really line up so perfectly at baseline? We correct a wide variety of abnormalities that lead to blood pressure control. Filtration fraction in particular is of interest.

Despite these somewhat disquieting facts, it is impossible to ignore the primary message in this paper. For patients with difficult hypertension, it appears that we have something new to offer.

Disclosure No potential conflicts of interest relevant to this article were reported. 